\section{An Investigation of Gold/Ceramic and Gold/Glass Interfaces}

\author{
Evelyne Darque-Ceretti ${ }^{1}$, Doriane Hélary ${ }^{1}$, \\ Marc Aucouturier ${ }^{2}$ \\ 1 Ecole des Mines de Paris, CEMEF, (CNRS UMR 7635), \\ B.P. 207, F-06904 Sophia-Antipolis cedex \\ e-mail : evelyne.darque-ceretti@cemef.cma.fr, \\ doriane.helary@cemef.cma.fr \\ 2 Centre de Recherche et de Restauration des Musées \\ de France (UMR CNRS 171), 6 rue des Pyramides, \\ F-75041 Paris cedex 01 \\ e-mail : marc.aucouturier@culture.gouv.fr
}

\begin{abstract}
:
This paper describes how various characterisation methods can be used to investigate the physicochemical and spectral properties of gold films in contact with glass or ceramic. The interface between the metal and substrate has been given special attention. The examples chosen to illustrate this include: liquid gold films (decorated and fired) or inlayed gold layers on ceramic wares and "sandwich" gold foils between two glass sheets for mosaic application. Characterisation methods include: microanalytical scanning electron microscopy, X-ray diffraction, ion beam analyses (PIXE: particle induced X-ray emission; RBS: Rutherford back-scattering spectrometry), photo-spectrometry and colorimetry. The adhesion mechanism and colour behaviour of the coated objects is discussed.
\end{abstract}

Gold films coated on, or in contact with, oxides (glass or ceramic) have a great number of artistic and technological applications. Gold has been used to decorate ceramic and glass for centuries, e.g. mosaic art and more recently gold films are used in high technology areas to modify surface properties. In most applications, the colour is of great importance, and also the strength and durability of the films. The nature of the adhesion at the interface between coating and substrate is vital in terms of durability. Information about the adhesion mechanism may be obtained by a physicochemical investigation at high resolution.

\section{Gold on Glass and Ceramic; a Summarised state-of-the-art}

Since ancient time, gold has been an attractive material for its bright magnificent aspect and its plasticity. We consider in this study, glass and ceramic surfaces decorated with gold. The use of gilded films on oxide substrates to decorate glass and ceramic wares is very old and may be dated from the Roman period (ca 1st century AD). Glass is a non-crystalline material usually constituted of fused silica with several additional oxides ( $\mathrm{Na}_{2} \mathrm{O}, \mathrm{K}_{2} \mathrm{O}, \mathrm{Al}_{2} \mathrm{O} 3$...); " "glass paste" ("pâte de verre") which has a composition distinct from usual glass is often partly crystallised. Ceramics, usually obtained through firing of clay earth, are a complete mixture of oxides containing several crystalline phases. Today thin gold coatings are used in several technological applications for which all unique properties of gold (high electrical conductivity, high corrosion and oxidation resistance, high reflectivity especially to infrared light, etc.) are taken into consideration.

A complete description of the history and techniques of the gold decoration processes on glass and ceramic, is not given in this summary, but may be found in a recently published comprehensive review (1).

\section{Gold Foil Coating (GFC)}

GFC is the most ancient technique used during Roman period. An apogee of the mosaic art is the Byzantine style, present in the famous Ravenne mosaics (2). In this process, a gold foil (some micrometer thick) is placed between two layers of vitreous materials. A transparent glass, which may be coloured or not, is placed on the top and the substrate is ceramic, glass paste or glass. The gold foil is pasted onto the substrate with an adhesive agent such as linseed oil or egg white, covered with glass powder and heated. From the XVth century, the technology was improved by covering the gold with melted glass. Gold foil is still used by Italian mosaic craftsmen: a gold foil is applied onto a circular wet glass or glass paste plate (about $1 \mathrm{~mm}$ thick) which is then covered by molten glass. This triple-layered material is then reheated up 
to $1200^{\circ} \mathrm{C}$ and cooled gradually to room temperature, with several annealing stages.

\section{"Liquid gold" Coating}

This process is relatively recent, being patented in 1851. The gold-bearing solution is a metallo-organic compound Au-S-R, where $\mathrm{R}$ can be an alkyl radical (3). Gold is very reactive with sulphur, and this explains why the two elements are often associated. The formation enthalpy of the Au-S bonding $(\Delta \mathrm{H}$ $=-165 \mathrm{~kJ}$ mole $^{-1}$ ) favours the formation of gold-sulphur compounds. Liquid gold contains typically 10 to $12 \%$ pure gold and the organic compound is dispersed as a suspension in natural spirits. Small quantities of soluble organic rhodium compounds or other additives such as indium or tin compounds are often added to promote the film brightness and adhesion. The mixture is applied on the surface with a brush, spray, or by printing process. The object is then heated in order to decompose and volatilise the organic compounds, leaving a thin metallic gold film.

\section{The Causes of Adhesion}

Some authors (4) suggest that the reason for good adhesion may be found in a strong chemical binding, of ionic-covalent type, between gold and oxygen at the substrate/gold interface:

$$
\begin{gathered}
\text {-Au-Au-Au-/O-Au-O-Au-/O-Si-O-Si- } \\
\text { metal oxide glass }
\end{gathered}
$$

The only existing gold oxide $\mathrm{Au}_{2} \mathrm{O}_{3}$ is unstable, with a formation enthalpy of $-13 \quad \pm 2.4 \quad \mathrm{~kJ}^{\mathrm{mole}} \mathrm{m}^{-1}$ and a decomposition temperature of $296^{\circ} \mathrm{C}$ (5).

Other authors (6) suggest the formation of Au-Si bonds, possible even at room temperature. Gold bonds to Si atom of $\mathrm{SiO}_{2}$ and reduces $\mathrm{SiO}_{2}$ to an intermediate oxidation state at the interface. A similar explanation (7) has been recently proposed in the case of $\mathrm{Al}_{2} \mathrm{O}_{3}$-gold adhesive interfaces, whose claim the successive formation of $\mathrm{AlAu}_{2}$ and $\mathrm{Al}_{2} \mathrm{Au}$ compounds, and a final oxidation of gold at the interface.

Another more reasonable explanation is diffusion. A temperature increase is able to induce a migration of gold into the substrate and conversely a migration of the substrate elements into the gold film. Katz et al. (8) report the existence of a diffusion of glass components into a coated gold film at $370^{\circ} \mathrm{C}$. The diffusion coefficient of gold in amorphous silica between $800^{\circ} \mathrm{C}$ and $1200^{\circ} \mathrm{C}$ has been found to be of the order of $1.710^{-17} \mathrm{~cm}^{2} . \mathrm{s}^{-1}(9)$. From Rapson (3) the adhesion of gold on lead glass (crystal glass) is good, and the diffusion coefficient of lead into gold is known to be somewhat important $\left(D_{\mathrm{Pb}}{ }^{\mathrm{Au}}=510^{-4} \mathrm{~cm}^{2} \cdot \mathrm{s}^{-1}\right.$ at $\left.800^{\circ} \mathrm{C}\right)(10)$.

\section{Possible Adhesion Improvement}

Adhesion of gold on an oxide substrate may be improved through several processes:
1) use of an intermediate metal film ( $\mathrm{Ti}, \mathrm{Cr}, \mathrm{W})$;

2) reactive sputtering $\left(\mathrm{O}^{2-}\right.$ bombardment);

1) $\mathrm{Ti}, \mathrm{Cr}$ and $\mathrm{W}$ are amphoterous metals, meaning that they are at the same time electron donors and acceptors. For instance, chromium is often used to insure adhesion between two electron donor metals (11). Those metals might then be able to favour electron exchanges and chemical binding between the two antagonists. Gold wets tungsten, titanium and chromium because its surface energy is low compared to that of these three metals (Table I).

2) Sputtering under $\mathrm{O}^{2-}$ bombardment has two combined consequences. The first is physical and results from a cleaning of the substrate and atomic "pushing" into the first substrate layers. This pushing effect creates atomic defects, which can promote preferential sites for gold particle binding. The second is chemical: oxygen contributes to the formation of oxides, even if they are unstable, in the interface region.

\section{Conclusion}

Several processes may be used to coat gold films or foils on oxide surfaces. Literature data on adhesion mechanisms, diffusion and/or chemical interactions are limited.

\section{Specimens and Methods \\ Specimens}

Two kinds of specimens are used in this investigation:

The first specimens are gilded glass mosaics prepared by closely following a method described in the state-of-the-art section of this article. The substrate is an opalescent glass paste prepared at high temperature treatment $\left(1200^{\circ} \mathrm{C}\right)$ of a complex mixture of silica sand, feldspath (sodium and potassium silico-aluminates), calcium fluoride $\left(\mathrm{CaF}_{2}\right)$, sodium nitrate and carbonate. The overlaying glass sheet is prepared from a remelted transparent glass paste containing less calcium fluoride. The composition and structure of both glasses are discussed in the results section. A gold-silver foil is laid on the transparent glass sheet, and the heated assembly is brought onto the substrate glass. The triplex is then rolled and slowly cooled to avoid thermal stresses. The mosaic pieces $\left(20 \times 20 \mathrm{~mm}^{2}\right)$ are cut from that plate. The final

Table I Surface energy (J.m-2) at melting temperature of gold, tungsten, titanium and chromium (12)

\begin{tabular}{|l|c|c|} 
& $\begin{array}{c}\text { Melting } \\
\text { temperature }\left({ }^{\circ} \mathrm{C}\right)\end{array}$ & $\begin{array}{c}\text { Surface energy } \\
\left(\mathrm{J} . \mathrm{m}^{-2}\right)\end{array}$ \\
\hline Gold & 1063 & 1.1 \\
\hline Tungsten & 3410 & 2.5 \\
\hline Titanium & 1668 & 1.7 \\
\hline Chromium & 1875 & 1.5
\end{tabular}


thickness is approximately $0.5 \mathrm{~mm}$ for the overlaying glass, about one micrometer for the gold foil, and $3 \mathrm{~mm}$ for the substrate.

The second specimens consist of white ceramic ware, a coffee cup and saucer in white glazed ceramic. The substrate compositions will be given in the results section of the paper. The saucer external border is decorated by the "liquid gold" method. An organometallic compound is applied by brush and then heated to a temperature of $780^{\circ} \mathrm{C}$. The exact composition of the solution was commercially sensitive. A final polishing brings the shining aspect. On figure 1, a red mark is observed. This red mark is a common fault in liquid gold application and is the result of colloidal gold colouration. The composition and structure of this mark will be described in detail in the results section.

The cup is decorated by "fine gold inlaying" (as described by the manufacturer) (Figure 1). The ceramic glaze is first carved and etched by hydrofluoric acid, preserving given areas through a bituminous varnish. Two layers of liquid gold are then applied: on the preserved zone, a layer of bright gold containing about $12 \%$ pure gold, fired between 850 and $900^{\circ} \mathrm{C}$; on the etched zone a layer of matte gold containing 24 to $28 \%$ pure gold fired at lower temperature $\left(800^{\circ} \mathrm{C}\right)$. A surface polishing step follows the application.

For the cup handle, two gold layers are applied (one shining and one matte) with an intermediary and a final annealing. The surface is then sanded and polished.

\section{Characterisation Methods and Specimen Preparation}

Scanning Electron Microscopy (SEM) was performed using a Philips environmental microscope and a LEO field-emission high-resolution microscope, either in SE (secondary electron) or BSE (back-scattered electron) mode. EDS (energy dispersive $\mathrm{X}$-ray spectrometry) microanalysis is performed when necessary, with a lateral resolution around $1 \mu \mathrm{m}$. The specimens are either observed directly on their surface or cut and polished (SiC disks, $1 \mu \mathrm{m}$ diamond paste and colloidal silica) for observation and microanalysis of cross sections.

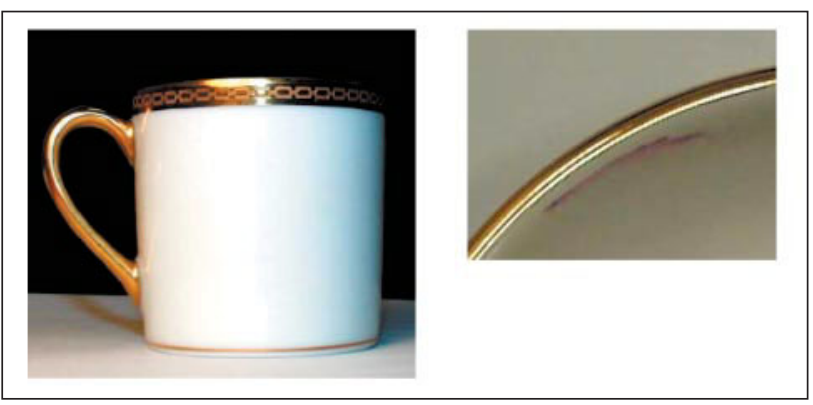

Figure 1 The investigated ceramic objects
X-ray diffraction was performed using a Philips diffractometer. X-ray diffraction provides the structure of crystalline compounds eventually contained in the layers and/or the substrates.

Ion beam analyses with the particle accelerator AGLAE, can provide proton, deuteron, or alpha particle beams up to $4 \mathrm{MeV}$ energy, focused on a spot of 30 to $100 \mu \mathrm{m}$ diameter (13). The beam is extracted to free atmosphere for analyses. A flow of helium gas is provided over the surface of the specimens in order to minimise particle energy degradation and straggling induced by the atmosphere. PIXE (particleinduced X-ray emission spectrometry) under proton or alpha beam of $3 \mathrm{MeV}$ energy and RBS (Rutherford back-scattering spectrometry) under the same proton or alpha beam are used. The PIXE and RBS experiments can be conducted simultaneously on the same irradiated area. Monte-Carlo simulation by the TRIM code (14) is used to estimate the thickness explored by the proton or alpha beam: on the basis of a $1 \mu \mathrm{m}$ gold layer overlaid on common glass one finds a maximum penetration range of $40 \mu \mathrm{m}$ for $3 \mathrm{MeV}$ protons and $5 \mu \mathrm{m}$ for $3 \mathrm{MeV}$ alpha particles; the same $40 \mu \mathrm{m}$ penetration exists for $3 \mathrm{MeV}$ protons in a sandwich of $20 \mu \mathrm{m}$ glass over $1 \mu \mathrm{m}$ gold over glass substrate. The ceramic specimens are submitted directly to the particle beam in open atmosphere, under a flow of helium gas. In the case of sandwich gilded mosaics, the upper glass layer is too thick and has been mechanically polished (SiC and zirconium oxide polishing). The remaining glass layer is between zero and a few micrometres thick

PIXE gives an average composition of the specimen over a depth larger than $20 \mu \mathrm{m}$ under $3 \mathrm{MeV}$ protons and a few $\mu \mathrm{m}$ under $3 \mathrm{MeV}$ alpha particles.

RBS provides spectra of the particles elastically backscattered from the specimen. A full analysis of the spectra, using the simulation code SIMNRA (15) leads to the depth distribution of elements from the surface, with a much higher accuracy for heavy elements than for light elements. The depth and mass resolutions are much better under alpha particles than under protons.

The simulation code for RBS spectra produces a distribution of the elements (in atomic concentration) as a series of discrete layers whose thickness is expressed in terms of number of atoms per square centimetre (at. $\left.\mathrm{cm}^{-2}\right)$. When a high number of elements, specially light elements ( $\mathrm{C}, \mathrm{H}, \mathrm{Si}, \mathrm{O}$, $\mathrm{Na}, \mathrm{K}, \mathrm{F}$ ), is present, when some layers might be porous, and when the interfaces exhibit a noticeable roughness, the simulation code may provide several possible solutions (16). In the results of simulations for the present study, we will then emphasise which information is considered reliable, and which may contain imprecise or unreliable data.

Spectro-photometry was performed using a goniospectro-photo-colorimeter working in back-scattering 
mode (17). This equipment illuminates the specimen with white light in the visible range (illuminant D65) under a given adjustable incidence angle over an area of $6 \mathrm{~mm}$ diameter, and collects the back-scattered light in the same direction. The visible part of this back-scattered light is dispersed in a spectrometer and the obtained spectrum is normalised versus the spectrum of a white standard. It is those normalised spectra, expressed in terms of "diffuse-reflectance" (\% of the white spectrum) which are compared to each other in the results section of this article. From the normalised spectra, it is also possible to obtain the colorimetric co-ordinates CIEL*a*b* (18) which qualify the colour of the extreme surface as regards to the $\mathrm{CIE}-1931$ colour standardisation.

\section{Structure and Physico-Chemistry of the Gold/Glass Interfaces Structure and microstructure}

The X-ray diffraction data indicate that the substrate is not entirely a vitreous material (Figure 2 ) and in addition to the broad ring characteristic of amorphous compounds, a series of fine lines are visible coming from crystallised compounds. All the lines are attributable to calcium fluoride $\left(\mathrm{CaF}_{2}\right)$. The overlaying transparent glass is confirmed to be entirely amorphous. Observations of cross sections by optical microscopy (Figure 3) confirm that the substrate material is heterogeneous and contains $\mathrm{CaF}_{2}$ crystals, identified by point microanalysis, whereas the transparent glass looks homogeneous. Back-scattered electron mode in scanning electron microscopy, shows clear evidence of the gold foil. In particular, the roughness of the interface is evidenced, as well as the occurrence of macroscopic and microscopic voids due to adhesion defects. Cracks in the gold foil are also observed as bright zones in transmission optical microscopy.

\section{Physico-Chemistry}

Physico-chemical characterisations have been performed on the two glasses by SEM-EDS microanalysis. The results obtained, before the mosaic processing, are shown in Table II.

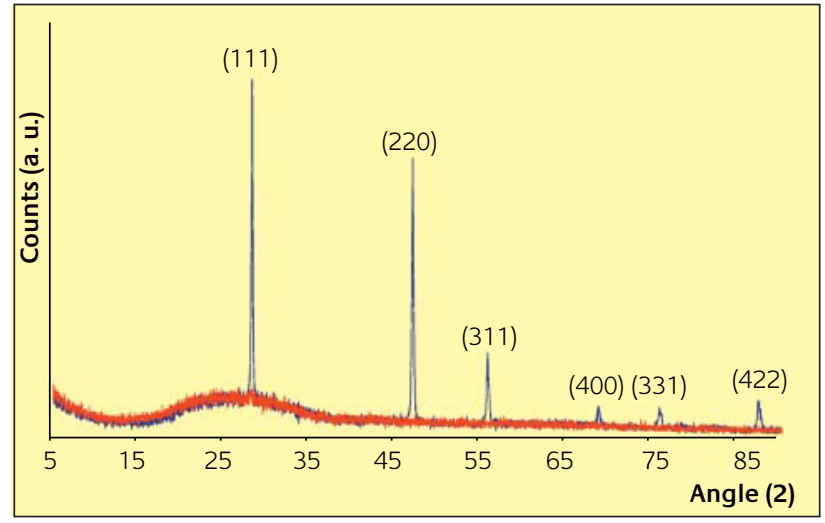

Figure $2 X$-ray diffraction diagram on the two glasses of the sandwich mosaic specimen: glass paste substrate (blue); transparent overlaying glass (red)

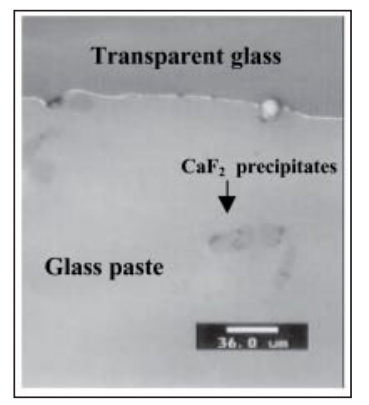

Figure 3 Optical micrograph of a gilded mosaic cross-section. Gilded foil is evidenced by the bright line between the transparent glass (dark grey) and the glass paste (light grey). The glass paste contains $\mathrm{CaF}_{2}$ microcrystals

They do not take into account the possible occurrence of carbonated or nitrated compounds. They are expressed in terms of atomic concentrations (Table Ila), useful for the comparison with nuclear analyses, and in terms of oxide and fluoride contents (Table IIb), assuming that fluorine is present only as calcium fluoride $\mathrm{CaF}_{2}$.

The gold foil contains 48.1 wt \% gold and 51.9 wt \% silver (respectively 33.7 at. \% Au and 66.3 at \% Ag). The CIE L*a*b* coordinates measured by the gonio-spectro-photo-colorimeter working in back-scattering mode are $: L=54, a^{*}=-2.4, b^{*}=+7.0$.

Table Ila: Elemental chemical analysis (at. \%) of the two glasses (average of multiple analyses)

\begin{tabular}{|c|c|c|c|c|c|c|c|}
\hline Glass specimen & 0 & $\mathbf{F}$ & $\mathrm{Na}$ & Al & Si & K & $\mathrm{Ca}$ \\
\hline Substrate (glass paste) & 54.8 & 6.9 & 6.8 & 1.3 & 23.0 & 0.4 & 6.6 \\
\hline Transparent glass & 57.5 & 4.1 & 8.4 & 1.4 & 24.6 & 0.3 & 3.2 \\
\hline
\end{tabular}

Table IIb: Composition (weight \%) of the two glasses (average of multiple analyses)

\begin{tabular}{l|c|c|c|c|c|c|}
\hline Glass specimen & $\mathrm{SiO}_{2}$ & $\mathrm{CaF}_{2}$ & $\mathrm{Na}_{2} \mathrm{O}$ & $\mathrm{Al}_{2} \mathrm{O}$ & $\mathrm{K}_{2} \mathrm{O}$ & $\mathrm{CaO}$ \\
\hline Substrate (glass paste) & 64.9 & 12.7 & 10.0 & 3.2 & 0.9 & 8.2 \\
\hline Transparent glass & 72.6 & 7.7 & 12.6 & 3.6 & 0.8 & 2.8
\end{tabular}


The area close to the interface has been analysed by SEMEDS in cross sections, two types of experimental artefacts may hinder the validity of the results.

In spot microanalysis by SEM-EDS method, the analysed volume is much larger than the diameter of the electron beam, especially in light materials as silicate glass. As an approximation, the projected diameter of the analysed region is larger than $2 \mu \mathrm{m}$ in glass and $0.5 \mu \mathrm{m}$ in gold, under the $20 \mathrm{kV}$ electron acceleration voltage used here.

As the hardness of gold is lower than that of glass, the polishing process used for cross section preparation may induce artificial broadening of the gold layer onto the examined surface. This may produce a false assessment of the foil thickness and of the possible concentration gradients measured by lateral step profiling.

Indicative spot analyses and lateral profiling have nevertheless been performed. Glass components are detected also in small quantities in the gold foil. Inversely, small amounts of gold and silver are detected in the glasses, mainly in the transparent overlaying glass.

RBS profiling of the triplex specimen have been conducted under $3 \mathrm{MeV}$ proton beam to obtain information on the concentration gradients.

Due to the nature of the RBS spectra, the simulation results shown in Figure 4 and Table III are only extracted from one of the solutions of spectra simulation through the SIMNRA code. The thickness in micrometre given in Table III for the different layers is an approximation $\left(10^{15}\right.$ at. $\mathrm{cm}^{-2} \approx 0.2$ $\mathrm{nm}$ ) which does not take into account a possible deviation from theoretical density.

Layer 1 represents a hydrated and/or porous glass layer, which may be altered by the specimen preparation procedure (prolonged grinding to reach the interface);

Layers 2 to 6 have the composition of the transparent

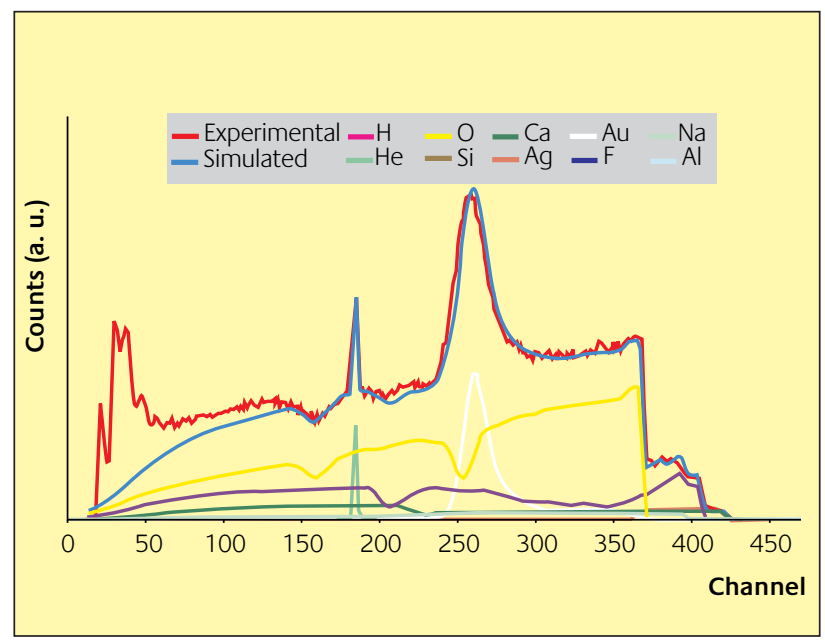

Figure 4 RBS experimental and simulated spectra for the sandwich mosaic specimen. Incident beam: $3 \mathrm{MeV}$ protons. SIMNRA simulation (see table III). The experimental spectrum and points are red; the simulated spectrum is blue; the other lines are individual simulated spectra of the elements (see inset)

glass with a growing concentration of $\mathrm{Au}$ and Ag. They represent a diffusion gradient of those two elements in the overlaying glass;

Layers 7 and 8 represent the remaining Au-Ag layer. In this simulation, it contains glass elements but with a low silicon content, probably as a combined consequence of its high roughness and high porosity.

Another simulation attempt found that, if the layers 7 and 8 were merged into one layer considered as compact Au-Ag alloy with flat interfaces, this would contain $38010^{15}$ at. $\mathrm{cm}^{-2}$ gold and $77010^{15}$ at. $\mathrm{cm}^{-2}$ silver, but would be much thinner (1150 $10^{15}$ at.cm ${ }^{-2}$, i.e. approximately $\left.0.23 \mu \mathrm{m}\right)$. These gold and silver quantities of a supposed compact layer should be compared with the quantities of $42410^{15}$ at. $\mathrm{cm}^{-2}$ Au and $84810^{15}$ at.cm ${ }^{-2}$

Table III Results of SIMNRA simulation of a triplex specimen, expressed as a succession of discrete layers (concentrations in at.\%)

\begin{tabular}{|c|c|c|c|c|c|c|c|c|c|c|c|}
\hline Layer \# & $\mathrm{Au}$ & $\mathrm{Ag}$ & Si & $\mathrm{O}$ & $\mathrm{Na}$ & $\mathrm{Ca}$ & Al & $\mathbf{F}$ & H & Thickness $\left(10^{15}\right.$ at. $\left.\mathrm{cm}^{-2}\right)$ & Approximate thickness $(\mu \mathrm{m})$ \\
\hline 1 & - & - & 10 & 30 & 5 & 2 & 1 & 5 & 47 & 18000 & 3.6 \\
\hline 2 & 0.02 & 0.04 & 30 & 49 & 10 & 4 & 2 & 5 & - & 70000 & 14 \\
\hline 3 & 0.25 & 0.5 & 30 & 48 & 10 & 4 & 2 & 5 & - & 42000 & 8.4 \\
\hline 4 & 0.5 & 1 & 30 & 47.5 & 10 & 4 & 2 & 5 & - & 10000 & 2 \\
\hline 5 & 1 & 2 & 27 & 49 & 10 & 4 & 2 & 5 & - & 8000 & 1.6 \\
\hline 6 & 2 & 4 & 24 & 49 & 10 & 4 & 2 & 5 & - & 5000 & 1 \\
\hline 7 & 8 & 16 & 6 & 49 & 10 & 4 & 2 & 5 & - & 2000 & 0.4 \\
\hline 8 & 12 & 24 & 8 & 35 & 8 & 3 & 2 & 8 & - & 2200 & 0.44 \\
\hline 9 & 0.1 & 0.2 & 27 & 46.7 & 8 & 8 & 2 & 8 & - & Substrate & Substrate \\
\hline
\end{tabular}


Ag contained in the porous \# 7 and \# 8 layers of Table III; Layer 9 has the composition of the glass paste substrate.

\section{Discussion and Interpretations}

It is important to emphasise the clear physical evidences proven by this study:

1) The mosaic substrate glass paste is not entirely amorphous and contains $\mathrm{CaF}_{2}$ crystals embedded in a vitreous matrix. Its overall composition is given in Table II;

2) The overlaying glass is homogeneous and compact, the composition is given in Table II;

3) The interfaces between the Au-Ag foil and both glasses are highly rough and the foil itself is probably porous. As a consequence of this roughness and porosity, it is difficult to know, from the simulations reported e.g. in Table III, which layer(s) represent the actual gold foil: layers $7+8$ or layers $6+7+8$ ? In the first hypothesis, the remaining gold foil contains about $125010^{15}$ at. $\mathrm{cm}^{-2}$ metal $(\mathrm{Ag}+\mathrm{Au})$; in the second hypothesis, it contains $158010^{15} \mathrm{at}_{\mathrm{cm}} \mathrm{cm}^{-2}$;

4) A diffusion of the Au-Ag foil components has occurred into both glasses. In the substrate paste glass, this leads to a uniform content of 0.1 at. \% gold and 0.2 at. \% silver over several micrometres. In the overlaying glass, a gradient is clearly evidenced (layers 2 to 5 or 2 to 6 of Table III), indicating a slow diffusion process;

5) It is difficult to appreciate if a diffusion of the glass components into the Au-Ag foil has occurred.

The diffusion of the Au-Ag foil components into the transparent glass of the mosaic may have occurred either during heating of the transparent glass-foil assembly before its application onto the glass paste, or during high temperature rolling of the triplex. Diffusion into the substrate has occurred during rolling. The diffusion coefficient of gold into amorphous silica has been measured to be of the order of $\mathrm{D}=1$ to $2 \cdot 10^{-7} \mathrm{~cm}^{2} \cdot \mathrm{s}^{-1}$ between 800 and $1200^{\circ} \mathrm{C}(12)$ and this value allows a diffusion over several $\mu$ m during a few seconds annealing at such temperature ((Dt) $)^{1 / 2}=10 \mu \mathrm{m}$ for $\left.\mathrm{t}=10 \mathrm{~s}\right)$.

The uniform metal distribution in the substrate indicates a rapid diffusion of small quantities over a distance larger than $10 \mu \mathrm{m}$ (this distance is an estimation obtained from the computation of the proton penetration into the specimen by the TRIM code). This diffusion into the substrate may be attributed to the presence of the interfaces of the $\mathrm{CaF}_{2}$ crystallised component in this material or to a possibly more porous structure.

Diffusion has consumed a great part of the gold foil: the remaining foil contains between 1200 and $160010^{15} \mathrm{at}_{\mathrm{cm}} \mathrm{cm}^{-2}$ $\mathrm{Au}+\mathrm{Ag}$, depending on the interpretation of the simulation, whereas the integrated quantity of the diffused $\mathrm{Au}+\mathrm{Ag}$ elements into both glasses is larger than $120010^{15}$ at. $\mathrm{cm}^{2}$ for all simulations taken into account. This means that nearly half of the foil has diffused into the glasses.
The nature of the bonding of the gold foil is thus different for the two interfaces. With the overlaying transparent glass, the bonding is clearly obtained by the formation of a diffusion gradient layer. With the substrate, the bonding, if it exists, has to be a consequence of physico-chemical bond formation between both glasses for instance through the cracks of the gold foil. Such conclusions have important consequences on the behaviour of the interfaces, for instance the ageing behaviour of the mosaic (19).

\section{Structure and Physico-Chemistry of the Gold/Ceramic Interfaces Microstructure}

Optical and conventional SEM observations of the gold layers on the two ceramic objects in Figure 1 do not reveal significant information on their microstructure. An interesting observation on the inlayed gold at the upper region of the cup (Figure 5) is that the Greek-like engravings of that layer appear very porous and rough, the remaining gold film is smoother. This will aid interpretation of the physico-chemical analyses.

High resolution scanning electron microscopy reveals more information. The field-emission microscope was operated at a very low voltage ( 1 to $2 \mathrm{kV}$ ) to obtain images at very high magnification (up to $x$ 100000). This low voltage does not allow EDS-microanalysis. The observations were restricted to the red mark visible near the edge of the gilded border of the saucer (Figure 1) which revealed fine spherically-shaped nano-particles with homogeneous size 25-40 nm and distribution (Figure 6a) and are identified as colloidal gold particles. This will be confirmed by the physicochemical analyses and by the spectroscopic investigations.

The white ceramic ware reveals micro-particles of heterogeneous size (100 to $300 \mathrm{~nm}$ ) and rectangular shape (Figure 6b). X-ray diffraction indicates $\mathrm{ZrSiO}_{4}$ and from the opacifying agent of the ceramic glaze.

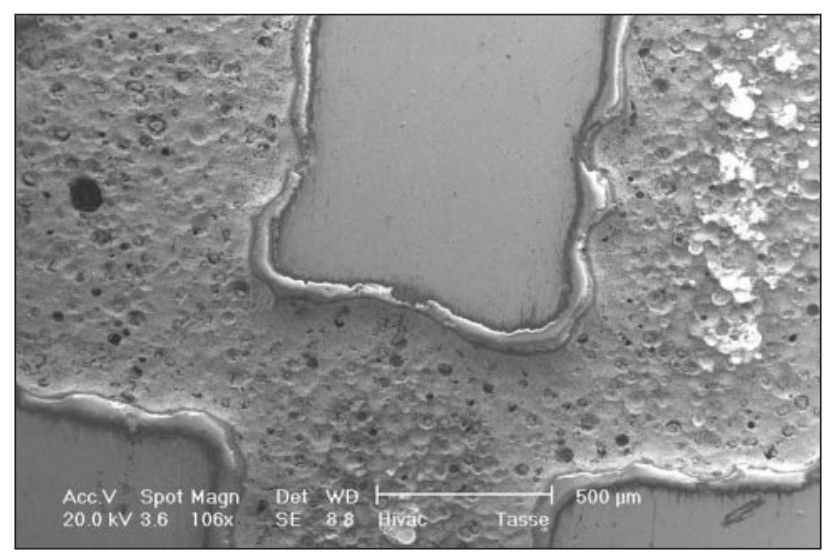

Figure 5 Scanning electron micrograph of the cup top edge gilded region, showing the inlayed gold surface and the porous engraved region 


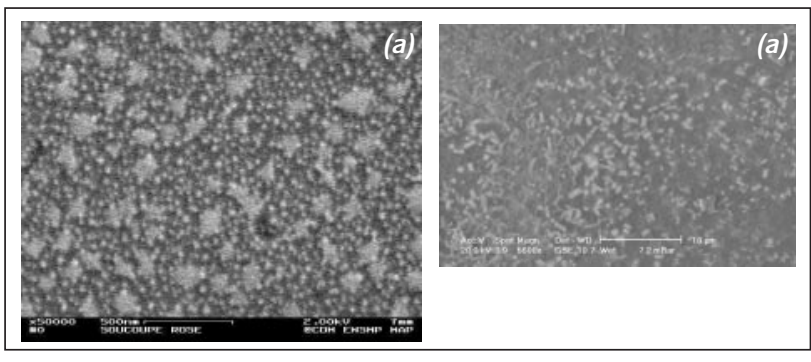

Figure 6 Scanning electron micrographs on the saucer surface. (a): high-resolution image in the red mark region; (b): image on the bare ceramic

\section{Physico-Chemistry}

The two ceramics were analysed by PIXE. Both are silicatebased. A quantitative explanation of the results is not given, because, segregation effects and heterogeneous distribution of the elements occurs. Table IV describes the elements, with their approximate respective importance.

The cup surface glaze has a simple analysis: silicon, oxygen, calcium and alkaline elements, it also contains iron as an impurity. The saucer surface glaze is much more complex: in addition to the preceding elements significant amounts of $\mathrm{Zn}, \mathrm{Zr}, \mathrm{Pb}$, Ba are present. Zn and Zr are usually added to ceramics as opacifying/whitening agents.

PIXE qualitative analysis on the gilded regions show that all gold layers contain silver, which cannot be quantified at this stage. Additives such as rhodium and other metals are either not detected or detected in very low amount (less than a few tens of ppm).

To obtain the stratification of the surface layers, RBS has been used in both configurations: under $3 \mathrm{MeV}$ proton beam (named RBS-proton) for the cup gilding layers, and under $3 \mathrm{MeV}$ alpha particle beam (named RBS-alpha) for all gilding layers. Figures 7,
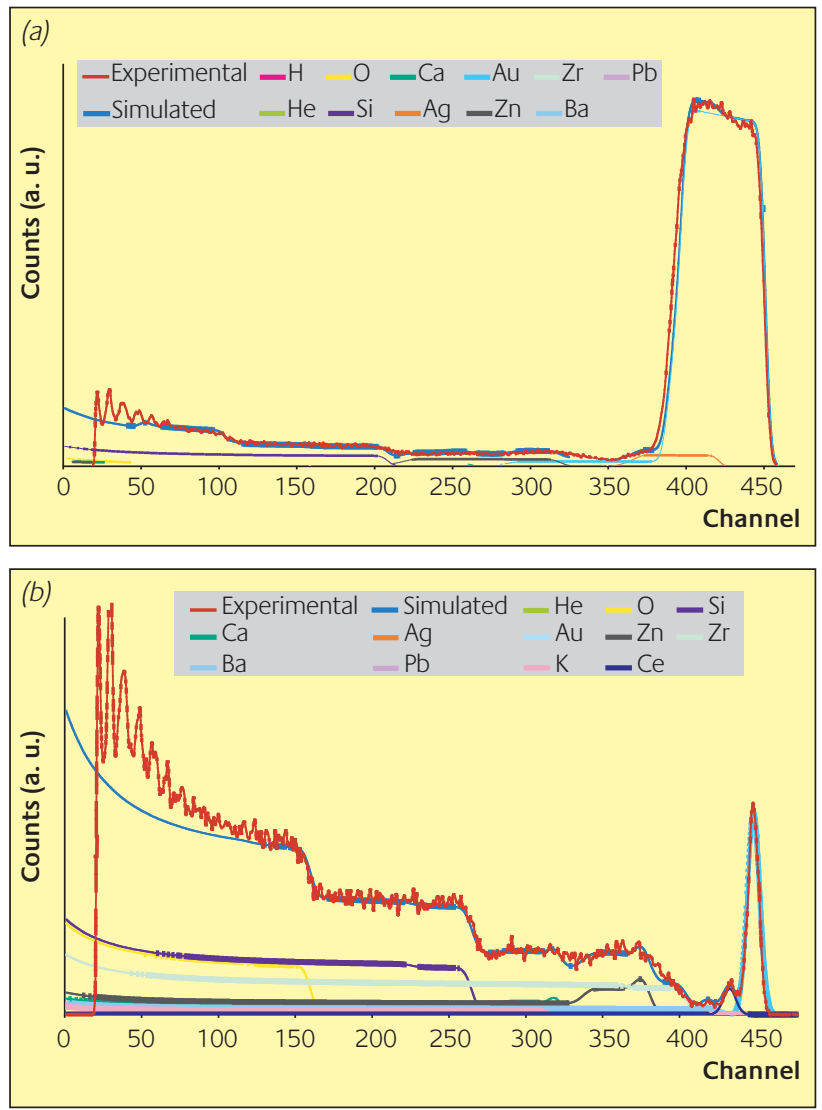

Figure 7 RBS experimental and simulated spectra for the saucer surface. (a): gilded region; (b): red mark. SIMNRA simulation (see tables $V$ and VI). The experimental spectra and points are red; the simulated spectra are blue; the other lines are individual simulated spectra of the elements (see insets)

and 8 show examples of simulated RBS-alpha spectra. The bare ceramics were also analysed in the same configuration, to aid the validation of simulations on the coated surfaces.

Table IV Qualitative PIXE analyses of the ceramics

\begin{tabular}{|c|c|c|c|c|c|c|c|c|c|c|c|}
\hline Specimen & Si & 0 & $\mathrm{Ca}$ & $\mathrm{Na}$ & K & Al & $\mathrm{Ba}$ & $\mathrm{Pb}$ & $\mathrm{Zn}$ & $\mathrm{Zr}$ & $\mathrm{Fe}$ \\
\hline Saucer & major & major & ++ & + & + & + & - & - & + & - & 0 \\
\hline Cup & major & major & ++ & - & - & - & 0 & 0 & 0 & 0 & ++ \\
\hline
\end{tabular}

Signification of symbols: ++: principal addition; +: addition; -: low amount; --: trace; 0: absent

Table V Results of SIMNRA simulation (RBS-alpha) of the gilded edge of the saucer, expressed as a succession of discrete layers (concentrations in at.\%)

\begin{tabular}{|l|c|c|c|c|c|c|c|c|c|c|c|c|c|c|}
\hline Layer \# & $\mathbf{C}$ & $\mathbf{H}$ & $\mathbf{A u}$ & $\mathbf{A g}$ & $\mathbf{O}$ & $\mathbf{S i}$ & $\mathbf{Z n}$ & $\mathbf{C a}$ & $\mathbf{B a}$ & $\mathbf{Z r}$ & $\begin{array}{c}\mathbf{N a} \\
\mathbf{+} \mathbf{K}\end{array}$ & $\mathbf{P b}$ & $\begin{array}{c}\text { Thickness } \\
\left(10^{15} \mathrm{at} / \mathrm{cm}^{2}\right)\end{array}$ & $\begin{array}{c}\text { Approximate } \\
\text { thickness }(\mu \mathrm{mm})\end{array}$ \\
\hline $\mathbf{1}$ & $\sim 38,4$ & $\sim 30,1$ & 29 & 2,5 & & & & & & & & & 3350 & $\sim 0,67$ \\
\hline $\mathbf{2}$ & $\sim 44,5$ & $\sim 40$ & 5 & 0,5 & 10 & & & & & & & & 1000 & $\sim 0,2$ \\
\hline $\mathbf{3}$ & & & & & 71,4 & 22 & 3,1 & 2,5 & 0,15 & 0,5 & $\sim 1$ & 0,02 & 6900 & $\sim 1,4$ \\
\hline $\mathbf{4}$ & & 0,1 & & 73,1 & 21,9 & 1 & 2,5 & 0,15 & 0,2 & $\sim 1$ & 0,02 & Substrate \\
\hline
\end{tabular}



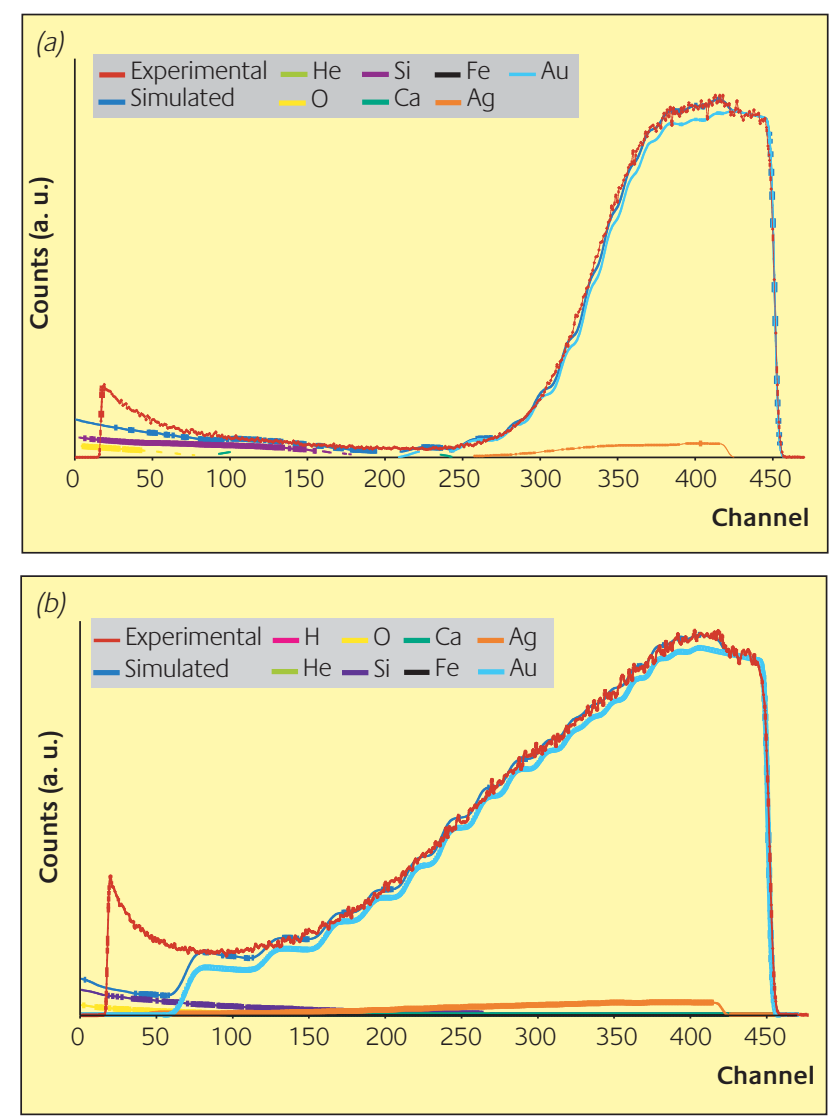

Figure 8 RBS experimental and simulated spectra for the cup surfaces. (a): handle gilded region; (b): top edge gilded region. SIMNRA simulation (see tables VII and VIII). The experimental spectra and points are red; the simulated spectra are blue; the other lines are individual simulated spectra of the elements (see insets)

\section{Gilding stratification on the saucer}

The stratification from the gilded surface of the saucer edge, as revealed by SIMNRA simulation of RBS-alpha is given in Table $\mathrm{V}$, expressed as a succession of discrete layers.

The gold layer appears compact and relatively thin but strongly contaminated with carbon and hydrogen, probably remaining from the gilding preparation (an organometallic compound decomposed by heating). Moreover, an intermediate contamination layer (\# 2 in Table V) exists between the gold layer and the substrate. The presence of oxygen (without silicon) already in that layer could be indicative of the formation of an oxidised gold (+ silver) interfacial compound (see $\S$ "the causes of adhesion"). A small quantity of gold has diffused into the substrate. The gold layer presents an atomic Au/Ag ratio of about 10 .

Layer \# 3 has the composition of the substrate, but exhibits a noticeable segregation of the elements $\mathrm{Zn}$ and $\mathrm{Zr}$.

The surface stratification of the region of the red mark is given in Table VI.

The thickness of the layer \# 1 is given with the hypothesis that it is compact, which is obviously not true (see Figures 1 and 6). The simulation is not able, for such small quantities, to make the difference between a compact very thin layer and an even distribution of larger particles over the substrate. It gives only the total quantity (25 $10^{15}$ at.cm ${ }^{-2}$ ) of metallic elements displayed at the surface. This will be discussed in the following section.

The layer \# 2 shows surface contamination by cerium oxide $\mathrm{CeO}_{2}$, This contamination has also been evidenced on the RBS analysis of the bare ceramic. Cerium oxide is a component of the polishing paste of hard ceramics, and the observed contamination is a consequence of surface preparation before gilding.

\section{Gilding stratification on the cup}

As previously described, the cup is gilded on its handle and by "inlaying" on its top edge. This inlay is engraved with a Greeklike design (Figure 1). All the regions were analysed by RBSproton and RBS-alpha (Figure 8). As the gold layers are thick, RBS-proton is used for a preliminary rough simulation that takes into account the composition of the substrate and the eventual presence of carbon contamination at the interfaces. RBS-alpha is then used for a precise simulation of the stratification.

Tables VII and VIII give the results of the SIMNRA simulations, still expressed as a succession of discrete layers, for both the handle and the top edge.

As seen from these results and from Figure $8 \mathrm{a}$ the gold layer of the handle (which contains also about 10 at. \% silver) appears quite thick. Only a thin layer (\# 1, about $0.16 \mu \mathrm{m})$ is compact, due to surface polishing. The other layers (\# 2 to

Table VI Results of SIMNRA simulation (RBS-alpha) of the red mark on the saucer, expressed as a succession of discrete layers (concentrations in at.\%)

\begin{tabular}{|c|c|c|c|c|c|c|c|c|c|c|c|c|c|}
\hline Layer \# & $\mathrm{Ce}$ & $\mathrm{Au}$ & $\mathrm{Ag}$ & 0 & Si & $Z n$ & $\mathrm{Ca}$ & $\mathrm{Ba}$ & $\mathrm{Zr}$ & $\begin{array}{l}\mathrm{Na} \\
+\mathrm{K}\end{array}$ & $\mathrm{Pb}$ & $\begin{array}{c}\text { Thickness } \\
\left(10^{15} \mathrm{at} / \mathrm{cm}^{2}\right)\end{array}$ & $\begin{array}{l}\text { Approximate } \\
\text { thickness (nm) }\end{array}$ \\
\hline 1 & & 90 & 10 & & & & & & & & & 25 & $\sim 5$ (particles) \\
\hline 2 & 33 & & & 67 & & & & & & & & 16 & $\sim 3$ (particles ?) \\
\hline 3 & & & & 50 & & 25 & 25 & & & & & 70 & 14 (particles) \\
\hline 4 & & & & 71,8 & 20,6 & 2,5 & 2,5 & 0,15 & 1,4 & $\sim 1$ & 0,02 & 3000 & $\sim 600$ \\
\hline 5 & & & & 73,1 & 21,6 & 1 & 1,7 & 0,15 & 1,5 & $\sim 1$ & 0,02 & Substrate & \\
\hline
\end{tabular}


Table VII Results of SIMNRA simulation (RBS-alpha) of the handle of the cup, expressed as a succession of discrete layers (concentrations in at.\%)

\begin{tabular}{|c|c|c|c|c|c|c|c|c|}
\hline Layer \# & $\mathrm{Au}$ & $\mathrm{Ag}$ & Si & 0 & $\mathrm{Ca}$ & $\mathrm{Fe}$ & Thickness $\left(10^{15} \mathrm{at} \mathrm{cm}^{-2}\right)$ & Approximate thickness (nm) \\
\hline 1 & 90 & 10 & & & & & 800 & $\sim 160$ \\
\hline 2 & 85 & 8,5 & 2,2 & 4,3 & & & 300 & $\sim 60$ \\
\hline 3 & 78 & 7,8 & 4,7 & 9,5 & & & 400 & $\sim 80$ \\
\hline 4 & 73 & 7,3 & 6,7 & 13 & & & 500 & $\sim 100$ \\
\hline 5 & 62 & 6,2 & 10,8 & 21 & & & 400 & $\sim 80$ \\
\hline 6 & 50 & 5 & 13 & 25 & 7 & & 400 & $\sim 80$ \\
\hline 7 & 35 & 3,5 & 18 & 36,5 & 7 & & 500 & $\sim 100$ \\
\hline 8 & 22 & 2,2 & 23 & 45,8 & 7 & & 600 & $\sim 120$ \\
\hline 9 & 12 & 1,2 & 26,50 & 53,3 & 7 & & 800 & $\sim 160$ \\
\hline 10 & 6 & 0,6 & 29 & 57,4 & 7 & & 1000 & $\sim 200$ \\
\hline 11 & 3 & 0,3 & 30 & 59,7 & 7 & & 1000 & $\sim 200$ \\
\hline 12 & 1,5 & 0,15 & 30,5 & 60,85 & 7 & & 1700 & $\sim 340$ \\
\hline 13 & 0,5 & 0,05 & 31 & 61,45 & 7 & & 5000 & $\sim 1000$ \\
\hline 14 & & & 33 & 63,7 & 3 & 0,3 & substrate & \\
\hline
\end{tabular}

Table VIII Results of SIMNRA simulation (RBS-alpha) of the gilded top edge of the cup, expressed as a succession of discrete layers (concentrations in at.\%)

\begin{tabular}{|c|c|c|c|c|c|c|c|c|c|}
\hline Layer \# & $\mathrm{Au}$ & $\mathrm{Ag}$ & $\mathrm{Si}$ & 0 & $\mathrm{Ca}$ & $\mathrm{Fe}$ & “H” & Thickness $\left(10^{15} \mathrm{at}^{\mathrm{cm}} \mathrm{cm}^{-2}\right)$ & Approximate thickness (nm) \\
\hline 1 & 60 & 6 & 10 & 20 & & & 4 & 1700 & $\sim 340$ \\
\hline 2 & 53 & 5 & 10 & 20 & & & 12 & 500 & $\sim 100$ \\
\hline 3 & 50 & 5 & 11,8 & 21 & & & 12,2 & 500 & $\sim 100$ \\
\hline 4 & 43 & 4,3 & 13 & 27,5 & & & 12,2 & 600 & $\sim 120$ \\
\hline 5 & 37 & 3,7 & 16 & 31,1 & & & 12,2 & 600 & $\sim 120$ \\
\hline 6 & 33 & 3,3 & 17 & 34,5 & & & 12,2 & 600 & $\sim 120$ \\
\hline 7 & 30 & 3 & 18 & 36,8 & & & 12,2 & 600 & $\sim 120$ \\
\hline 8 & 26 & 2,6 & 20 & 39,2 & & & 12,2 & 800 & $\sim 160$ \\
\hline 9 & 23 & 2,3 & 21 & 43,7 & & & 10 & 1000 & $\sim 200$ \\
\hline 10 & 19 & 1,9 & 23 & 46,1 & & & 10 & 1000 & $\sim 200$ \\
\hline 11 & 15 & 1,5 & 24,5 & 49 & & & 10 & 1200 & $\sim 240$ \\
\hline 12 & 11 & 1,1 & 26 & 51,9 & & & 10 & 1200 & $\sim 240$ \\
\hline 13 & 8 & 0,8 & 27 & 54,2 & & & 10 & 1500 & $\sim 300$ \\
\hline 14 & 6 & 0,6 & 27,5 & 55,9 & & & 10 & 1500 & $\sim 300$ \\
\hline 15 & 4 & 0,4 & 29,5 & 59,1 & & & 7 & 2200 & $\sim 440$ \\
\hline 16 & 2,5 & 0,25 & 30 & 60 & & & 7,25 & 3000 & $\sim 600$ \\
\hline 17 & & & 30 & 60 & 3 & 0,3 & 6,7 & substrate & \\
\hline
\end{tabular}

11 or 12) simulate either a diffusion gradient or a rough and/or porous interface extending over several micrometres. The RBS analysis of the bare substrate revealed that the substrate is porous. The present simulation indicates that either the porosity has been filled up by gold during the process or that gold has diffused in the substrate over more than $1 \mu \mathrm{m}$ (layers \# 12 and 13).
It is important to underline that the simulation given in Table VIII corresponds to the thick region of the gilding of the top edge. Other analysis performed on different regions of that area showed that the overall thickness of the goldcontaining layers is heterogeneous, varying between 5000 and $2000010^{15}$ at. $\mathrm{cm}^{-2}$ from the lower part to the upper part. Moreover, a RBS analysis performed inside the Greek-like 
design shows a small quantity of gold at the surface, as can be shown from the SEM observation (Figure 5).

The gold-containing layer appears (Figure 8b) thick, and, the gold quantity decreases slowly towards the substrate composition over a large overall thickness. No compact gold layer is observed at the surface. The gold layer itself is porous, and the substrate is sufficiently porous and/or rough to allow a deep progressive "diffusion" of the metallic elements. The hydrogen ("H") level given in Table VIII may be only an indication of a closed porosity.

\section{Discussion and Interpretations}

The structure and physico-chemistry of the gold/ceramic interfaces studied in this work can only be interpreted by combining the results obtained from all the various techniques.

The gilding of the saucer edge, reveals a thin gold layer (less than $1 \mu \mathrm{m}$ ) contaminated by carbon and hydrogen, resulting from an incomplete decomposition of the organometallic liquid gold. Segregation of the glaze whitening elements ( $\mathrm{Zn}$ and $\mathrm{Zr}$ ) has occurred at the glazegold interface during the processing. Diffusion of a small quantity of metal into the substrate has occurred.

The red mark present near the gilded region of the saucer is clearly colloidal gold particles.

The enrichment in $\mathrm{Zn}$ and $\mathrm{Ca}$ at the surface of the ceramic is evidenced by RBS.

The gilded layers on the cup are surprisingly quite similar: as seen from the comparison of Figures $8 \mathrm{a}$ and $8 \mathrm{~b}$. The gold layer of the handle is thinner than the top edge, but the penetration of the metallic elements into the substrate is nearly equivalent. This penetration is a consequence of the porosity of the substrate and of the deposition process. It may be the same for both regions. The structure and physico-chemistry of the gilded layers is different for the saucer (Figure 7a: compact layer, presence of carbon and hydrogen, no penetration into the substrate) than that for the cup handle (Figure 8a: porous layer, absence of carbon and hydrogen, deep penetration into the substrate).

The process used for the cup leads clearly to an important mechanical (eventually diffusion) mechanism of adhesion. In the case of the liquid gold application of the saucer, physicochemical interactions have to be considered to explain the adhesion.

\section{Spectro-Photometry and Colour of the Gilded Surfaces}

A spectro-photo-colorimetric investigation of the gilded regions of the ceramic objects (saucer edge, red mark near the saucer edge, handle of the cup, top edge of the cup) has been conducted. Back-scattered light from the specimen illuminated by a white light in the visible range is collected and the obtained diffuse reflectance spectra are, after normalisation to a white reference, recorded in the visible 380-780 nm wavelength range. The illumination-collection angle is chosen to be 22 degrees, after a preliminary study showing that specular reflection is negligible at that angle, in the back-scattering configuration.

\section{Results and Interpretations}

Figure 9 shows examples of the obtained diffuse reflectance spectra on all the areas covered with a continuous gold layer, together with the spectrum obtained on a pure gold surface.

The diffuse reflectance factor values (ordinate value) are difficult to compare from one specimen to another, because the surface is not flat, and the investigation angle may vary: for these metal surfaces, the reflectance is very sensitive to the illumination angle. Moreover, the "surface state"

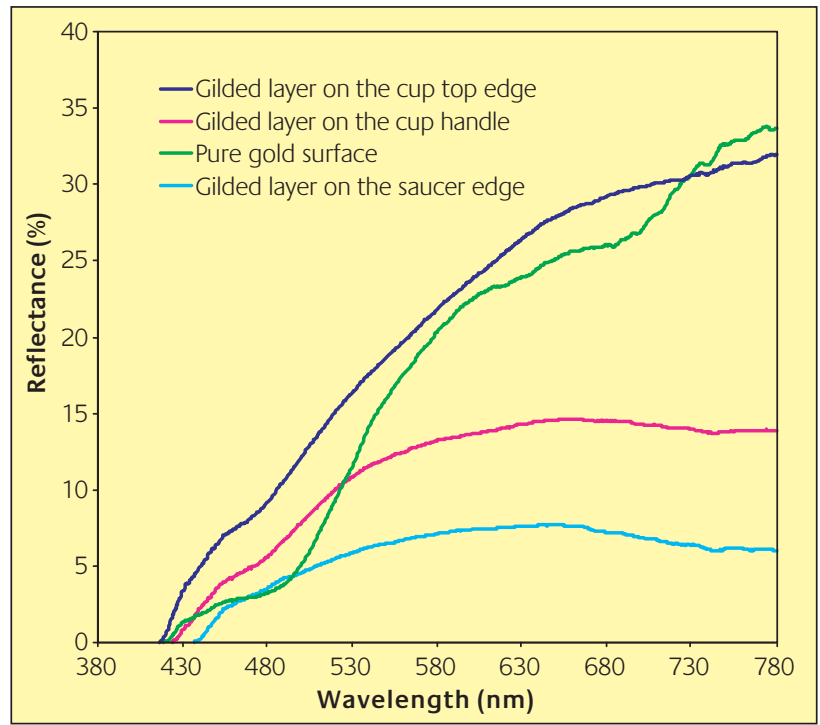

Figure 9 Optical spectra of back-scattered visible light obtained on the gilded regions of the cup and saucer

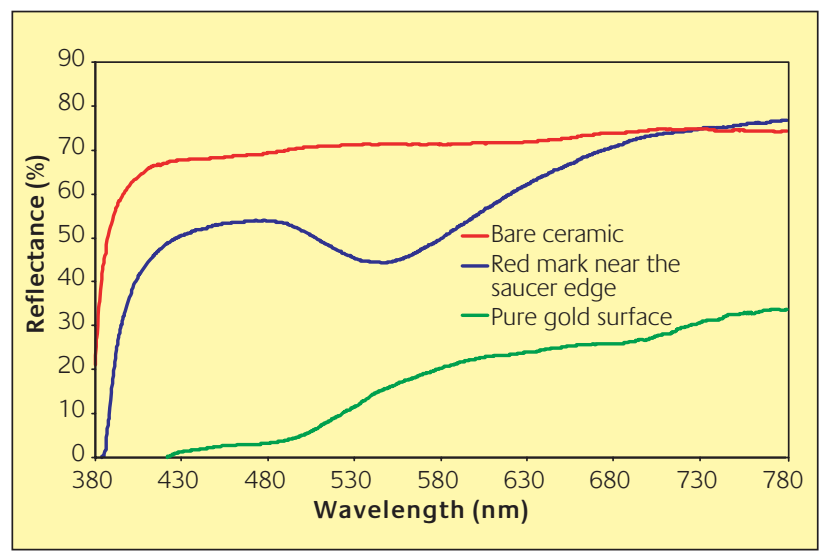

Figure 10 Optical spectrum of back-scattered visible light obtained on the red mark of the saucer 
(roughness) is known to have a strong influence on the value of the diffuse reflectance factor (17), and it is shown from the preceding investigation that the roughness may vary in large proportion from one specimen to another. Therefore, the spectra of Figure 9 should only be compared to the values of the wavelengths corresponding to "accidents" occurring in the curve shape, such as slope change or absorption bands.

From Figure 9, it appears that the continuous gilded regions exhibit comparable spectra, with a pronounced slope change around 460-480 nm wavelength. This is characteristic of the spectrometric behaviour of gold surfaces (20). The differences in the "wavelength break", from $420 \mathrm{~nm}$ for the cup top edge to $430 \mathrm{~nm}$ for the cup handle and $442 \mathrm{~nm}$ for the saucer edge, may be attributed to different surface states of these regions. In the large wavelength range, one should also note a difference between the cup top edge on one side and the other two regions (cup handle and saucer edge) and the gold reference on the other side. The cup top edge shows a relatively higher response (a more positive slope of the spectrum) in the red range. This may be due to the fact that, as shown in the physico-chemical investigation (Table VIII, layer \#1), the extreme surface of the cup top edge gold layer is porous, whereas all other surfaces are compact (see Table $\mathrm{V}$, layer \#1 and Table VII, layer \#1).

The diffuse reflectance spectrum on the red mark of the saucer is shown in Figure 10. This spectrum is entirely different from the other spectra and exhibits a strong absorption band with a minimum diffuse reflectance factor at $550 \mathrm{~nm}$. This absorption band is related with the colloidal nature of the red gold deposit in this region. Many works have been published concerning the optical properties of nanometric or colloidal gold or various metal clusters (21-24 and references herein included). It is known that colloidal metallic particles absorb light in well-defined region of the visible spectrum. This

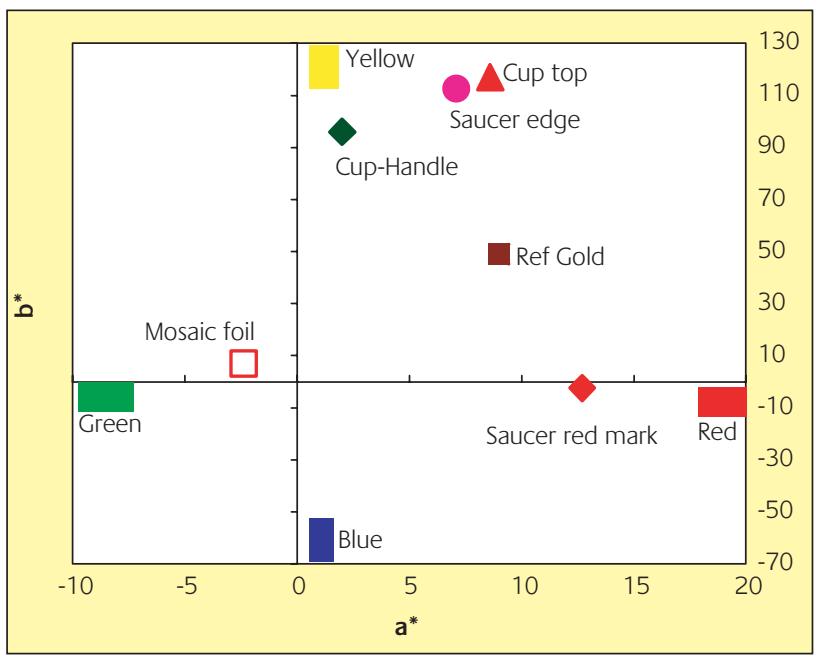

Figure 11 CIE $L^{*} a^{*} b^{*}$ co-ordinates of the various specimen surfaces property has even been used for colouration of glasses or glazes, for instance "Purple of Cassius" (25). The wavelength of the absorption band depends on the nature and composition of the metal and on the mean diameter of the particles. Referring to the existing published data (22), it is possible to estimate with good accuracy the diameter of the gold particles. Here the band at $550 \mathrm{~nm}$ indicates that the mean diameter of the presumably spherical particles is around $40 \mathrm{~nm}$. This is in good agreement with high resolution SEM (Figure 6) observations. The SEM observation indicate the presence of smaller gold particles (between 25 and $40 \mathrm{~nm}$ ). From the cited reference, this should lead to an absorption band at lower wavelength, however the particles here contain silver, known to decrease the surface plasmon energy of the Au-Ag clusters (24).

From the obtained spectra, and through a computation code (26), the colour of the investigated areas in term of colour co-ordinates in the CIE L*a*b* system is described (Figure 11).

\section{Discussion}

The interpretation of the back-scattered optical spectra on metal surfaces is difficult. The literature refers usually to absorption or specular reflection spectra. The spectra of the actually gilded regions, may be affected by reflection due to the non-planar surface. Interpretations are therefore qualitative. Variations in the positions in the $L^{*}{ }^{*} \mathrm{~b}^{*}$ diagram may be attributed to variations in the surface polish, or on the surface roughness and porosity, and also to the composition of the gilding layer. A comparison may be made with Figure 5 with the review paper by Cretu and van der Lingen (20). The chroma values are higher in the present study, comparisons should however be made with care, as the measurement equipment and configuration may be different. Positive values of $a^{*}$ confirm a noticeable amount of alloying element, silver. It can be stated that the observed backscattered spectra and the resulting L*a*b* diagrams are a good way for identification of a true gilded surface.

\section{General Conclusion}

This detailed study of the gilding layers on glass and ceramic objects has shown the ability of the presently available investigation methods to identify the nature, and the physico-chemical and structural organisation of complex surface systems. However only the combination of the various methods, can lead to a complete and reliable description of the surface layers and of the interfaces between these layers and the different substrates.

The gold-glass interfaces of the "sandwich" mosaics are shown to be highly porous and rough. The bonding mechanisms are highly dependent on the nature of the glass in contact with the gold foil. 
The bonding mechanism of gold on ceramics is strongly related with the coating process.

The spectrometric investigation, coupled with high resolution SEM, has shown interesting results regarding the nature and size of the gold colloidal particles present on the saucer.

\section{Acknowledgements}

The authors wish to acknowledge the help of :

Joseph Salomon (C2RMF, Paris) for all ion-beam analysis experiments;

François Grillon (Centre des Matériaux, Ecole des Mines de Paris) for high resolution SEM;

Gabriel Monge (CEMEF, Sophia-Antipolis) for X-ray diffraction experiments;

Mady Elias (C2RMF, Paris) for spectrometric measurements and interpretations;

The manufacturer BERNARDAUD for the information about their specimens.

\section{About the Authors}

Evelyne Darque-Ceretti is a Senior Scientist at the Ecole des Mines de Paris. She works in the Centre for Material Forming (CEMEF) in the high technology science park, Sophia-Antipolis near Nice. She has expertise in material surface and interface characterisation methods, surface and interface physicochemical reactivity, adhesion and adherence (mechanical adhesion), for different kinds of materials (metals, inorganic, organic) and interfaces (metal/ceramic, metal/polymer, oxide/polymer, polymer/polymer).

Doriane Hélary is a research student, preparing a thesis focused on the structure, properties and process optimisation of gilded layers on glass and ceramic.

Marc Aucouturier is Directeur de Recherche (Senior Scientist) at the Centre National de la Recherche Scientifique (CNRS). He has developed expertise on material surface and interface characterisation methods, and more recently on ion beam analyses applied to cultural heritage objects.

\section{References}

1 G. Landgraf, in 'Cold Progress in Chemistry, Biochemistry and Technology', ed. by H. Schmidbaur, John Wiley and Sons, New York, 1999, 145-171

2 G. Bustacchini, Gold Bulletin, 1973, 6, 52

3 W.S. Rapson, Gold Bulletin, 1979, 12, 108

4 J.A. Pask, R.M. Fulrath, J. Am. Ceram. Soc., 1962, 45, 12, 592

5 M. Jansen, A.V. Mudring, in 'Cold Progress in Chemistry, Biochemistry and Technology', ed. by H. Schmidbaur, John Wiley and Sons, New York, 1999, 748-793

6 R.S. Bauer, R.Z. Bachrach, L.J. Brillson, Appl. Phys. Lett., 1980, 37, 11, 1006

7 T.P. Nguyen, J. Ip, P. Le Rendu, A. Lahmar, Surf. And Coatings Technology, 2001, 141, 108

8 A. Katz, S. Nakahara, M. Geva, J. Appl. Phys., 1991, 70, 12, 7343

9 G.H. Frischat, 'Ionic diffusion in oxide glasses', Trans Tech. Publications, Aedermannsdorf, 1975

10 P. Pascal, 'Nouveau traité de chimie minérale', T. 8, Masson et Cie, Paris, 1963

11 S.R. Cain, L.J. Matienzo, F. Emmi, J. Phys. Chem. Solids, 1989, 50, 1, 87

12 J.M. Howe, Int. Mat. Rev., 1993, 38, 5, 233

13 E. Ioannidou, D. Bourgarit, T. Calligaro, J-C. Dran, M. Dubus, J. Salomon, P. Walter, Nuclear Instruments and Methods in Physics Research B, 2000, 161-163, 730

14 J.F. Ziegler, J.P. Biersack, 'The stopping and range of ions in solids', John Wiley, London, 1999. Code SRIM 2000 available on: http://www.SRIM.org.

15 M. Mayer, SIMNRA ${ }^{\circledR}$ Max-Planck-Institut für Metallphysik, 1997-1998

16 J. Slotte, A. Laasko, T. Ahlgren, E. Rauhala, R. Salonen, J. Räisanen, A. Simon, I. Uzonyi, A.Z. Kiss, E. Somorjai, J. Appl. Phys, 2000, 87, 1, 140

17 M. Elias, M. Menu, Optics Comm., 2000, 180, 191

18 R.D. Overheim, D.L. Wagner, in: 'Light and Color', John Wiley and Sons inc., New York, 1982, 63, 253

19 M. Verità, in: 'I colori della luce', Marsilio Editori, Venizia, 1996, 41

20 C. Cretu, E. van der Lingen, Gold Technology, 2000, 30, 31

21 J. Turkevich, G. Garton, P.C. Stevenson, J. of Colloidal Science, 1954, 9, 26

22 C.F. Bohren, D.R. Huffman, 'Absorption and scattering of light by small particles', John Wiley and Sons, Chichester, 1983

23 U. Kreibig, M. Vollmer, 'Optical properties of metal clusters', Springer, Berlin, 1995

24 M. Gaudry, J. Lermé, E. Cottancin, M. Pellarin, J-L. Vialle, M. Broyer, B. Prével, M. Treilleux, P. Mélinon, Phys. Rev. B, 2001, 64, 085407

25 J. Zarzycki, 'Les verres et l'état vitreux', Masson, Paris, 1982

26 M. Elias, 2001, private communication 